\title{
Pharmacology and potential therapeutic uses of some cannabinoids
}

\author{
Roger G Pertwee*,1 \\ ${ }^{1}$ The School of Medicine, Medical Sciences and Nutrition, Institute of Medical Sciences, University of Aberdeen, Aberdeen AB25 \\ 2ZD, Scotland, UK \\ *Author for correspondence: rgp@abdn.ac.uk
}

Roger Pertwee speaks to Jennifer Straiton, Assistant Editor, at the BNA 2019 Festival of Neuroscience (14-17 April, Dublin, Ireland), where he gave a talk titled 'Pharmacological actions and potential novel therapeutic uses of certain plant and synthetic cannabinoids'. Roger Pertwee is an Emeritus Professor at the University of Aberdeen (Scotland, UK), where he has been active in scientific research since 1974. He began his research career at the University of Oxford (UK) where he gained three postgraduate degrees: an MA in biochemistry, a DPhil in pharmacology and a DSc in physiological sciences. His research focuses on the pharmacology of cannabinoids, both on their mechanisms of action and on their potential therapeutic uses. He has held major roles in multiple major discoveries in the field including; the discovery of a cannabinoid CB1 receptor allosteric site, the pharmacological characterization of various phytocannabinoids as well as the co-discovery of endocannabinoids and the co-discovery and characterization of novel synthetic cannabinoids.

Accepted for publication: 14 April 2019; Published online: 12 September 2019

Keywords: cannabinoids • pharmacology • therapeutics

Could you give a summary about what you will be discussing in your session and summarize what you think the key take away points from the talk will be?

I start by introducing cannabis and its constituents and then go on to talk about their modes of action. I also speak a bit about the cannabis-based medicines that already exist, in particular Sativex, which is for multiple sclerosis, and Epidiolex, which was very recently approved in the USA for treating childhood epilepsy, as well as potential new therapeutic uses for some plant cannabinoids. In the second half of the talk, I move onto the other side of the coin, as it were, and talk about the endogenous cannabinoid system; a system of receptors on which drugs like THC act alongside the chemicals of our own bodies that can activate those receptors. These endocannabinoid molecules are often released in a protective way, so I will be talking about potential new medicines which could exploit protective effects of the endocannabinoids.

\section{Could you tell me a bit about what research is going on in your lab right now?}

We are mainly focusing on synthetic cannabinoids at the moment, particularly drugs that act on CB1 receptors as allosteric modulators. When a drug directly activates a receptor it acts on the orthosteric site, though some receptors also have allosteric sites; sites we discovered in my lab a few years ago to be present on CB1 receptors. When you target an allosteric site you can strengthen or weaken the orthosteric activation of a receptor by a drug. This means we can strengthen the activation of CB1 receptors by endocannabinoids when they are released onto these receptors in a protective way.

\section{What kind of diseases would you be aiming for in developing these drugs?}

The endocannabinoid system is protective for a lot of disorders, one such being pain relief. Some of my collaborators and I have just published a paper showing that one of these allosteric modulators, which is called a positive allosteric modulator, strengthens the endocannabinoid-initiated activation of CB1 receptors to produce signs of pain relief in an animal model. It does so without producing any signs of dependence or tolerance so it could be a good medicine. However, it must be noted that this is just animal work, so clinical studies are still needed. 


\section{Where do you hope to see this area of research in 5-10 years?}

There is a huge amount of animal cannabinoid research data, so lots of discovered potential therapeutic uses of cannabinoids, either plant cannabinoids or synthetic cannabinoids, but what is needed now are clinical data from human subjects. It would also be useful to get input from people who self-medicate with cannabis or who act as carers by administering cannabis to unwell friends or family. To get input from them could prompt more research, initially with animals but subsequently with humans.

\section{Do you think that research in this area has been held back by societal pressures due to the association with marijuana and the legislation against use of cannabis?}

At one time it was, and the field was fading. What really changed things was the discovery of the endocannabinoid system because it suddenly became clear that, whether you like it or not, you will experience cannabinoid-induced effects. These effects are often beneficial, for example, endocannabinoids are released in a way which can reduce bad memories; when you wake up the memory of a bad dream fades very quickly and that is probably a result of endocannabinoids being released in the amygdala.

\section{Do you think the legalization of marijuana, as in Canada recently, will help with research as well or is that more societal?}

It could help, if we can get feedback from people taking it medically. Of course, lots of people will be taking it recreationally and the important thing, if you change the law in that way, is to minimize the harms that such a change can do and maximize the benefits. It would be good to reduce the black market, and it would be good to have standardized products which have been approved, because such products would be expected to cause minimal harm. Cannabis is very variable with many different strains, many different constituents in many different ratios to each other and some strains will be better for you than others. The same applies to medical use, again there will be some strains that are better to use than others. Also, it would be best to avoid dangers from things such as pesticides, sometimes used when growing the plant which should not get into any cannabis product.

Additionally, I think it is important to set an age limit, particularly for some of the strains that have a lot of THC in them. One of the roles of the endocannabinoid system is to help in the development of the brain, if you interfere with that by adding exogenous cannabinoids then that could have very serious consequences. It could, for example, increase the risk of becoming schizophrenic. We are talking here about children and adolescents, probably up to the age of about 25 for whom THC in cannabis can be dangerous, beyond that age it is probably less so.

\section{Where would you suggest people look if they are interested in finding out more information for cannabinoid use in neurological disorders?}

Useful sources of information for people interested in cannabinoids would include publications, particularly lots of reviews and books, and also societies which specialize in cannabinoids. The International Cannabinoid Research Society (ICRS) is one of these, and there is also the International Association for Cannabinoid Medicines (IACM) which has members that include clinicians and scientists as well as patients who self-medicate with cannabis.

Financial \& competing interests disclosure

RG Pertwee has a formal link with GW Pharmaceuticals. The author has no other relevant affiliations or financial involvement with any organization or entity with a financial interest in or financial conflict with the subject matter or materials discussed in the manuscript. This includes employment, consultancies, honoraria, stock ownership or options, expert testimony, grants or patents received or pending, or royalties.

No writing assistance was utilized in the production of this manuscript.

Interview disclosure

The opinions expressed in this interview are those of RG Pertwee and do not necessarily reflect the views of Future Medicine Ltd.

Open access

This work is licensed under the Attribution-NonCommercial-NoDerivatives 4.0 Unported License. To view a copy of this license, visit http://creativecommons.org/licenses/by-nc-nd/4.0/ 